\title{
A REVIEW ON DIGITAL MARKETING
}

\author{
Akshay Raju Tandava ${ }^{1}$, Ms. Vaishnavi Tiwadi ${ }^{2}$, Mr. Raman Dayama ${ }^{3}$

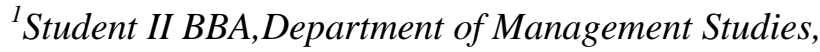 \\ Centurion University of Technology and Management, Vizianagaram \\ ${ }^{2}$ Student II BBA, Department of Management Studies, \\ Centurion University of Technology and Management, Vizianagaram \\ ${ }^{3}$ Student II BBA, Department of Management Studies, \\ Centurion University of Technology and Management, Vizianagaram
}

Article DOI: https://doi.org/10.36713/epra8602 DOI No: 10.36713/epra8602

\begin{abstract}
Digital marketing is the marketing of products or services using digital technologies, mainly on the Internet, but also including mobile phones, display advertising, and any other digital media. Digital marketing has gained full momentum due to technology revolution and sophisticated mobile technologies and as well as due to reasonable data prices. Marketers started different strategies like Search Engine Optimization, Search Engine Marketing, Content Marketing, Data analytics to reach the customers in a better and speedy way. The present study mainly highlights about different digital marketing components taken care of by the marketers for better customer reach and influence. The study is purely conducted with the help of secondary data.
\end{abstract}

KEYWORDS: Digital Marketing, Search Engine Optimization, Search Engine Marketing, search results

\section{INTRODUCTION}

Digital marketing is the recent buzz in the marketing arena where the marketer uses internet and technologies(Chaffey,2013) as a major platform to market goods and services. It is also called online marketing or web marketing. In simple terms digital marketing is all about driving more customers. At a high level, digital marketing refers to advertising delivered through digital channels such as search engines, websites, social media, email, and mobile apps. As customers became tech savvy, and due to rise in smart phone usage digital marketing has become efficient medium to reach the target customers across the globe.

\section{OBJECTIVES}

The major objective of the study is to have a comprehensive understanding of significance of digital marketing and different strategies adopted in digital marketing

\section{METHODOLOGY}

The study is mainly conducted with the help of secondary data exclusively. The data has been collected from published articles, published videos, published lectures etc.

\section{DIGITAL MARKETING}

All the activities which are performed as part of digital marketing process is consist as domain part of digital marketing 


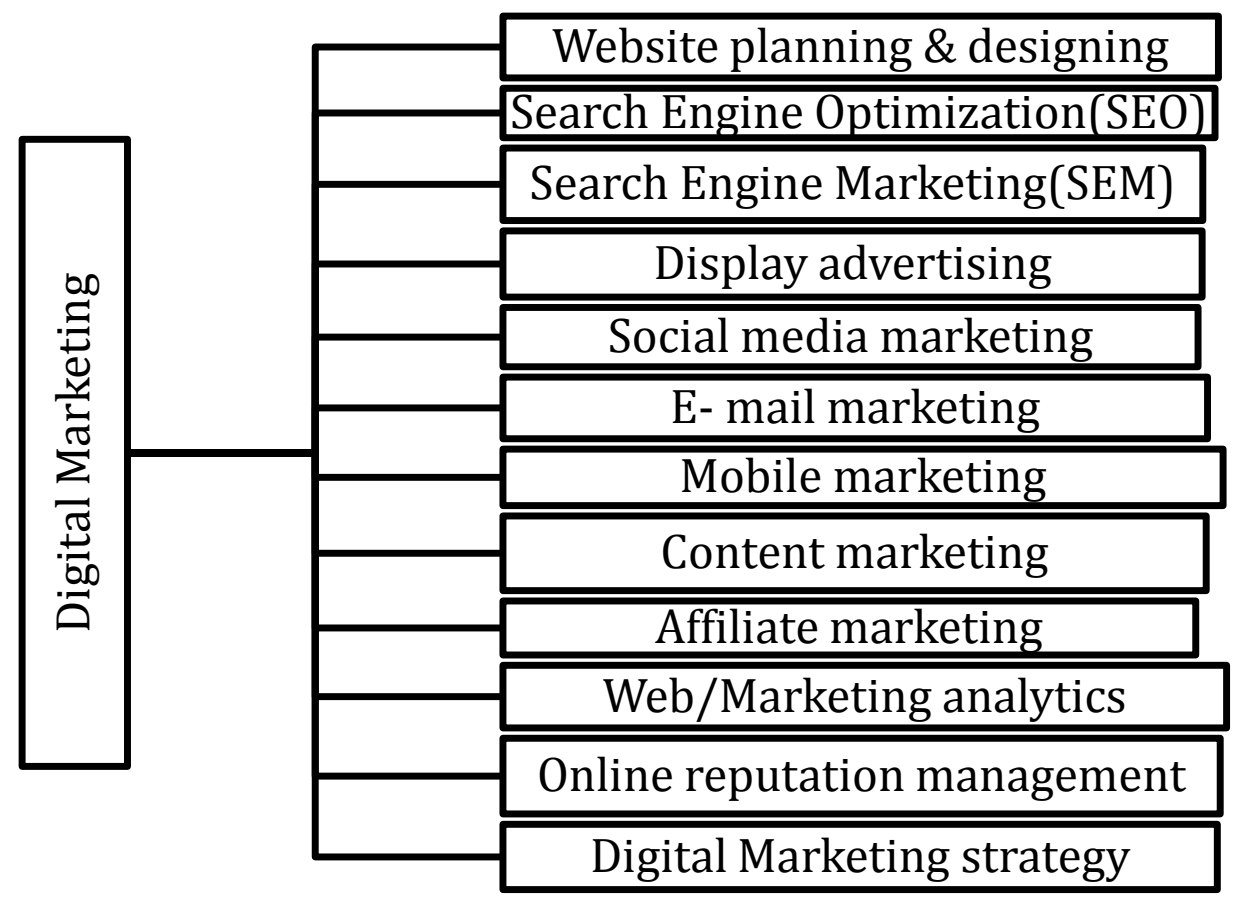

Picture: Components of digital marketing strategy

\section{WEBSITE DESIGNING}

Websites are the backbone of digital marketing campaigns and they play an important role in all digital marketing activities. A website is something that reflects a company in small computers, mobiles, laptops. Website is the face of any business that helps in attracting the customers and increases the shopping experience. All significant website aspects should be carefully identified before the website development process starts.

\section{WEBSITE PLANNING}

Creating a wireframe and sitemap is part of the website planning process. This is a crucial phase because it serves as the skeleton for any website that usually make take 2 weeks to 6 weeks to complete effectively. A user should be able to explore a site with ease, and this starts with the creation of a sitemap.

\section{WEBSITE DEVELOPMENT}

The term "web development" refers to the process of designing, developing, and maintaining websites. Web design, web publishing, web development, and database management are all included. Anyone can use a web-based interface to construct and edit their own website with these tools. (Milne, S. (2008))

\section{SEARCH ENGINE OPTIMIZATION(SEO)}

Search engine optimization is a process of improving a business site's visibility in search engine result pages that increases customer traffic to the website. SEO increases the amount of visits to a website by ensuring that it appears towards the top of a search engine's list of results. Integrating content with search engine optimization and social media marketing is the key to increasing visitors. (Davis, $\mathrm{H}$. (2006))

\section{SEARCH ENGINE MARKETING}

SEM (search engine marketing) is a digital marketing method for improving a website's presence in search engine results pages (SERPs). While the phrase used to refer to both organic and paid search operations like search engine optimization (SEO), it now nearly solely refers to paid search advertising. Paid search and pay per click are other terms for search engine marketing (PPC). Search engine marketing has become a critical online marketing approach for expanding a company's reach, as an increasing number of people study and shop for products online. In fact, the vast majority of new visitors to a website arrive from a search engine query. Search engine marketing (SEM) is a type of Internet marketing that entails improving the exposure of websites in search engine results pages, primarily through paid advertising. (Sen, R. (2005))

\section{DISPLAY ADVERTISING}

Digital display advertising is graphic advertising done on websites, applications, and social media platforms that uses text, photos, flash, video, and audio in the form of banners or other ad formats. The primary goal of display advertising is to provide 
site visitors with general adverts and brand messages. A display ad, often known as a banner ad, is a type of online paid advertising that consists of a professionally created image or photo, audio - video visual with a copy. Viewers can click on the promotional image to be taken to the appropriate landing page. (Tucker, C. (2011))

\section{SOCIAL MEDIA MARKETING}

Social media marketing is the utilization of social media stages and websites to advance an item or benefit. In spite of the fact that the terms emarketing and advanced promoting are still overwhelming in the scholarly community, social media promoting is getting to be more prevalent for both specialists and analysts. The use of social media platforms and websites to advertise a product or service is known as social media marketing. Social media marketing is growing more popular among practitioners and researchers.

\section{EMAIL MARKETING}

Email marketing is a method of informing people through email list about new products, promotions, and other services from the marketer. It can also be a softer sale to educate the audience about the brand's worth or keep them engaged in between transactions. It could also be anything in the middle. The act of sending a commercial message via email, usually to a group of people, is known as email marketing. Every email sent to a potential or current consumer might be considered email marketing in the broadest sense. It entails sending advertisements, soliciting business, or soliciting purchases or donations by email. (Jenkins, S. (2008)).

\section{CONTENT MARKETING}

In digital marketing content is king. Content marketing is a marketing strategy used to attract, engage, and retain an audience by creating and sharing relevant articles, videos, podcasts, and other media. This approach builds up mastery, advances brand mindfulness. The development and distribution of online content (such as films, blogs, and social media posts) that does not directly promote a brand but is designed to pique interest in its products or services.

\section{MOBILE MARKETING}

Mobile marketing involves marketing or promotion of products in the form of advertisements in smartphones, tablets or any other mobile devices. Mobile marketing strategy helps in identifying target consumers access location and time sensitive customized content that promotes products, services or ideas.

\section{AFFILIATE MARKETING}

Affiliate marketing is a technique of making money (commissions) by promoting and selling a company's products or services. It is a marketing agreement in which an online shop pays a third-party website a commission for traffic or sales created through its referrals.

\section{WEB / MARKETING ANALYTICS}

Marketing analytics is the process of assessing, controlling, and evaluating marketing performance in order to improve its efficiency and maximize return on investment (ROI). Understanding marketing analytics enables marketers to work more efficiently and save money on web marketing. The techniques and tools that enable marketers to assess the success of their marketing operations are referred to as marketing analytics. This is performed through the use of performance metrics (e.g., blogging versus social media versus channel communications)

\section{ONLINE REPUTATION MANAGEMENT}

Online reputation management (ORM) is when you actively monitor mentions of your business on websites and social media in order to handle any unfavorable or fraudulent remarks. Online reputation management (ORM) helps in actively monitoring mentions about business on websites and social media in order to handle any unfavorable or fraudulent remarks.

\section{DIGITAL MARKETING STRATEGY}

A digital marketing strategy is a plan that enables your company to achieve specific objectives by utilizing carefully chosen marketing channels such as paid, earned, and owned media. Setting marketing objectives based on market data and target audiences, selecting digital marketing channels and platforms, identifying channel-specific delivery strategies, and defining macro marketing KPIs to monitor digital marketing performance are all part of a digital marketing strategy.

\section{CONCLUSION}

Digital marketing is a strategy used to drive more number of customers with the help of search engine marketing, search engine optimization, online reputation management etc. In the current world of technology, Digital marketing has a strong role to play in marketing to persuade the customers and as well as increasing the business. As the trend is continued Digital marketing has become potential domain in marketing with innovative trends and strategies.

\section{REFERENCES}

1. Bhat, S. S., \& Milne, S. (2008). Network effects on cooperation in destination website development. Tourism Management, 29(6), 1131-1140. 
2. Chaffey. D (2013), "Definitions of E-marketing vs Internet vs Digital marketing”, Smart Insight Blog, February 16

3. Davis, H. (2006). Search engine optimization. O'Reilly Media, Inc.".

4. Duffy, D. L. (2005). Affiliate marketing and its impact on e- commerce. Journal of consumer marketing.

5. Goldfarb, A., \& Tucker, C. (2011). Online display advertising: Targeting and obtrusiveness. Marketing Science, 30(3), 389-404.

6. Jenkins, S. (2008). The truth about email marketing. FT Press.

7. Proserpio, D., \& Zervas, G. (2017). Online reputation management: Estimating the impact of management responses on consumer reviews. Marketing Science, 36(5), 645-665.

8. Rowley, J. (2008). Understanding digital content marketing. Journal of marketing management, 24(56), 517-540.

9. Saravanakumar, M., \& SuganthaLakshmi, T. (2012). Social media marketing. Life science journal, 9(4), 4444-4451.

10. Saura, J. R., Palos-Sánchez, P., \& Cerdá Suárez, L. M. (2017). Understanding the digital marketing environment with KPIs and web analytics. Future Internet, 9(4), 76.

11. Sen, R. (2005). Optimal search engine marketing strategy. International Journal of Electronic Commerce, 10(1), 9-25.

12. Varnali, K., \& Toker, A. (2010). Mobile marketing research: The-state-of-the-art. International journal of information management, 30(2), 144-151. 